$\mathbb{T}$ periodica polytechnica

Transportation Engineering

$41 / 1(2013) 65,69$

doi: 10.3311/PPtr. 7101

http://periodicapolytechnica.org/tr

Creative Commons Attribution (i)

RESEARCH ARTICLE

\section{Implications of Behavioural Economics for the Transport Sector}

\author{
Rita Markovits-Somogyi / Balázs Aczél
}

Received 2012-10-25

\begin{abstract}
Neoclassical economics relies on the assumption that decision makers make rational, coherent and efficient choices, and this has also been the basis for transport planning and policy making in the recent decades. Lately, however, it is becoming more and more evident that individuals, and thus also the participants of transport processes, do not always act rationally. Moreover, the logic behind this irrationality seems to be consistent and the relevant behavioural patterns predicting the given activities may well be revealed. The theoretical background of this research field is called behavioural economics and is gaining an increasing impetus on governmental and policy levels, especially in the USA and the UK. Thus, it is reasonable to utilize it in the fields of studying and influencing transport and mobility in daily and work life, and to apply its merits as a means to reduce the adverse effects of climate change induced by transport operations.
\end{abstract}

\section{Keywords}

behavioural economics $\cdot$ nudge $\cdot$ transport

\section{Rita Markovits-Somogyi}

Department of Transport Technology and Economics, Budapest University of Technology and Economics, Múegyetem rkp. 3., H-1111 Budapest, Hungary e-mail: rsomogyi@kgazd.bme.hu

Balázs Aczél

Faculty of Education and Psychology, ELTE, Izabella u. 46., H-1064 Budapest, Hungary

e-mail: aczel.balazs@ppk.elte.hu

\section{Introduction}

Behavioural economics is becoming a hot topic in the scientific literature. Growing number of articles recite studies where the findings of behavioural economics have been investigated or utilized in diverse fields. These include health related topics (e.g. [10], pension systems [23] and further financing issues [24].

In the United Kingdom, sensitivity to behavioural economics has already reached government level, where studies and guidelines are being issued to facilitate the incorporation of the applicable findings into practice. For instance, the Department for Transport has published its Behavioural Insights Toolkit in 2011. This paper gives concrete and down to the earth guidelines as how the key elements of behavioural economics can be utilized by local governments in choice architecture. Further, a reference report created in 2008 gives an overview of behaviour change models and their uses. In Denmark the 'Danish Nudging Network' (DNN) was created in December 2010 and it aims to establish a network of researchers, practitioners, stakeholders and policy-makers interested in using and developing, but also cautious about, the use of behavioural theory by public institutions, private organizations and as part of companies' CSR (corporate social responsibility) [6]. The nudge theory can be considered as a peer notion to behavioural economics, where a nudge can be seen as any aspect of the choice architecture that alters people's behaviour in a predictable way without forbidding any options or significantly changing their economic incentives [25].

The importance of behavioural economics can also be highlighted by the fact that several journals have been dedicated to this topic (Journal of Behavioral Finance, International Journal of Applied Behavioral Economics, Journal of Behavioral Finance \& Economics).

However, the possible applications of behavioural economics in the transport sector have not yet been elaborated in detail, and there is an increasing need for large-scale, panel and field studies in natural environments, just as it would be vital to understand the effect of cultural and geographic contexts as well [3]. Even more so, since several elements of behavioural economics could 
be used as a cost-effective tool in climate-change policies [17], and travel demand management has already been discovered as a way to influence travel behaviour [14]. It remains to be investigated, whether ex-post efficiency analysis can also be linked to this field [16].

\section{Methodology}

Neoclassical economics assumes the decision maker to be rational. It is supposed that she is informed about the different available alternatives; she knows the exact benefits of each alternative and thus, will make a rational choice by selecting the alternative providing her with the maximum benefit possible. However, it is becoming more and more clear that human decision makers do not function this way, moreover, their way of deciding can well be predicted, so they can be construed as "predictably irrational" [2]. It is these predictions that need to be incorporated in choice architecture, because these predictable behaviours will have a lasting effect on how individuals react to certain measures or processes. Within the context of behavioural economics the following human characteristics [5, 17] have a vital importance on decision making:

1 Individuals are loss averse: losing a certain amount of money will induce in them a larger negative effect than is the extant of pleasure experienced by winning the same amount. This fact has already been proved by Tversky and Kahneman as early as 1981 [26]. Figure 1]. shows the hypothetical value function expressing this relationship. Not only the steepness but the characteristic of the function is also different, which also implies that the gains relative to a smaller amount are appreciated more than the same gain compared to a higher amount. In practice, within the transport environment, this might mean that people are willing to undertake a longer walk in order to be able to avoid paying for an extra bus ticket (in the magnitude of $350 \mathrm{HUF}$ ), while, when purchasing a new bicycle, they would not considering going to a farther located retailer so as to save $350 \mathrm{HUF}$ off the (relatively higher) price.

2 They focus on changes, salient events have a large effect on them. Hence, the salient cost or experience of travelling and the end cost or experience may have a disproportionate impact on our transport behaviour [17].

3 It has been found repeatedly that individuals tend to overweigh small probabilities, and are e.g. willing to spend high sums in order to be able to totally exclude the chances of something from happening. This characteristic is displayed by the hypothetical weighting function shown in Fig. 2

4 Individuals are also generally bad at computing probabilities, and put too much weight on recent events, while they neglect the effects of far-off ones [5].

5 The presence of mental accounting is essential: different costs and incomes related to different topics are treated differently,

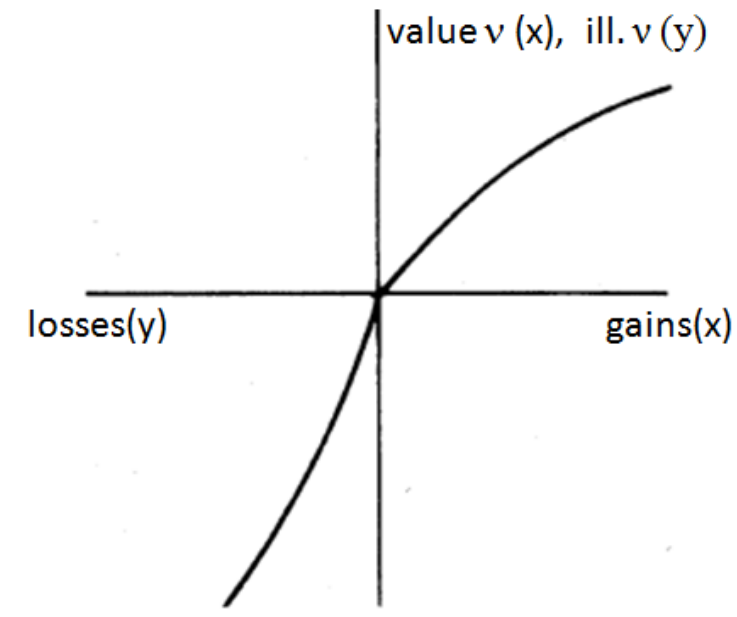

Fig. 1. Hypothetical value function mapped by Tversky and Kahnemann (1981) 26

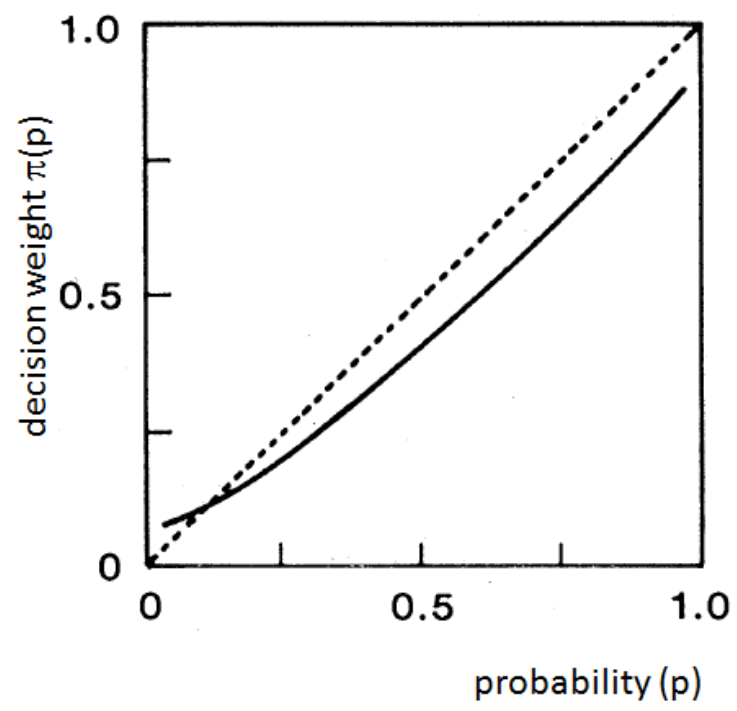

Fig. 2. Hypothetical weighting function mapped by Tversky and Kahnemann (1981) [26]

the extent of which depends on the given topic itself. E.g. they are trying to economize on money by choosing the petrol station offering the lowest prices, but will think completely differently of the same amount saved, if it is the difference between the prices of medicines containing the same agent.

6 Individuals care about other people and the opinion of significant others matter to them. This field opens up questions about how the behaviour of others shape our norms and decisions, also in the transport sector. The attitudes of family members, colleagues and friends might have a strong influence on whether we opt for public transport.

7 Financial incentives can have a negative impact on the choice of individuals. It has been found that putting a price tag on certain actions will move the activity from the field of social norms to that of market norms [12], and as such, motivations to do the right thing will depend on the appropriateness of 
the price or fine. Thus, money often turns out to be the most expensive way to motivate people [2].

Nudging, as a way to subtly prompt people into a behaviour advantageous to them, without limiting their freedom of choice has also to be highlighted as an essential element connected to behavioural economics. Within the transport sector, there have already been a few ideas implemented, which can be seen as nudges to act towards e.g. traffic calming (for instance the vehicle activated signs, which show the speed of the vehicle only if a certain speed limit has been surpassed [13]). The classical example is the white striped surface that becomes denser, as one approaches the dangerous crossing where speed needs to be reduced [25]. Also the human form signs deployed at the Hungarian roadsides several years ago may be construed as nudges in the area of traffic calming ("He was also expected at home Ôt is hazavárták").

However, nudges may be called for in more complex environments as well, where the decision maker faces choices, which are too numerous for her to be able to select the best option. Choice architecture is a term that has been coined in this field, meaning that experts creating the decision construct are responsible for the structure of the task, and will necessarily influence the final outcome by presenting the options in a given way. This influence is present even when there is no such intention from the side of the choice architects and the construct is seemingly random. Thus, saying that choice architecture is required only when we would like to deliberately manipulate the way how people choose is severely false. This is exactly why choice architects have to be aware of the results and consequences of their conduct. Very often the first step of this process is the need to realize that we are choice architects in a given field.

A third term that is to be clarified within this context is libertarian paternalism, which is the theoretical approach, when nudges are applied. The idea is that freedom of choice has to be maintained (i.e. libertarian), but choices need to be presented in a way that urge individuals to select the options best for them (hence paternalism). This could be a way to be followed by public bodies and institutions, ensuring better choice architectures [25].

Some researchers argue that nudges do not necessarily lead to a long-term change in behaviour, as these little spurs do only contribute to short-term changes and reactions [13], as they are not designed to influence the decision making process of the reflective system [3].

A reasonable way to integrate behavioural economics with the theme of transport science would be the MINDSPACE approach, which is a useful mnemonic to remember the main elements of this field [17]. Messenger, Incentives, Norms, Defaults, Salience, Priming, Affect, Commitment and Ego are the key areas which have to be investigated when considering any nudging in transport decision making.

\section{Interrelated research}

Reviewing the relevant scientific literature in the field, it can be stated that there are few articles, which deal explicitly with behavioural economics in the transport sector.

There is a larger body of work, which deals with the interdisciplinary areas of psychology and transport, but these do not necessarily evoke and apply the principles of behavioural economics or nudging.

One such relevant field is that of speeding, within the context of traffic safety. Speeding behaviour is frequently investigated by the theory of planned behaviour (TPB) [20], which explains, although not exclusively, but to a significant extent the individual's actions. It measures intention, instrumental and affective attitude, subjective and descriptive norm, self-efficacy, perceived controllability, moral norm, anticipated regret, selfidentity, and past speeding behaviour. TPB has been found to account for $68 \%$ of the variation in intention and $51 \%$ of the variation in subsequent behaviour [8].

Fuller et al. [11] in their review show that the concept of taskdifficulty homeostasis (see Fig. 3.) may also help in explaining speeding. This theory finds that drivers drive in such a way as to maintain the level of driving task difficulty within a preferred range.

Peer [18] in his research has shown, that the time-saving bias is also an important element predicting speeding. In their investigations, the time-saving bias predicted estimations of required speed better than any of these factors, and also better than drivers' age, gender, education and income, as well as the number of years they have had a license and their monthly driving kilometrage, their prior speeding violations and crash involvement. In predicting drivers' personal speed choices, the timesaving bias was second only to the frequency of committing ordinary violations [18].

In line with what has been cited in connection with taskdifficulty homeostasis, Peer and Rosenbloom [19] also pointed out, that, apart from the time-saving bias, sensation seeking also significantly contributes to the choice of speed.

A further related theme is the potential for car-use reduction, which could be achieved by hard and soft policy measures. Bamberg et al. [4] focus, within soft policy measures, on the potential inherent in personalized travel planning programmes. Research also shows that travel mode choice may be influenced by gender as well [22].

Car-use reduction is an issue strongly intertwined with the existing attitudes towards public transport. Articles looking into how in-vehicle activities affect commuter's satisfaction with public transport [9], or into the time perception experienced during an urban commute [15], just as much as papers investigating the connection between happiness and travel mode switching [1] have a significant relevance here. 
Fig. 3. The process of task-difficulty homeostasis [11]

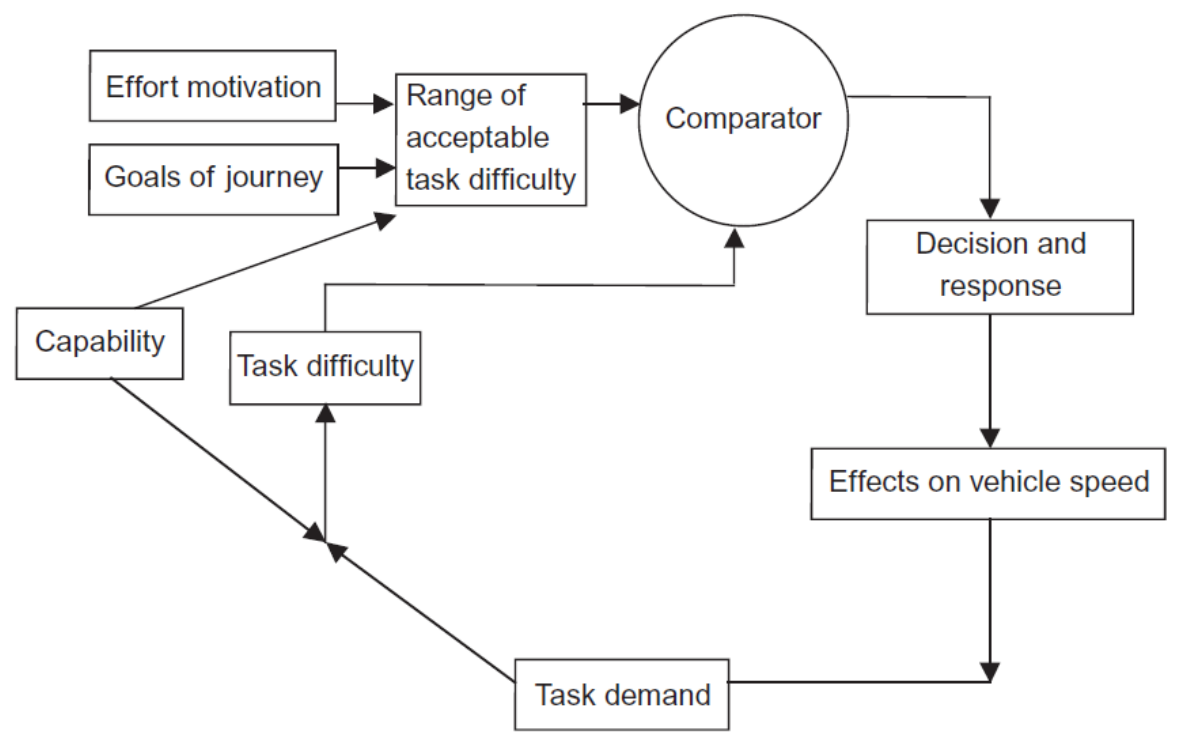

\section{Fields for development}

The possible areas for development are manifold. The most evident seems to be the theme of 'fostering car use reduction', which may include several sub-themes, like the change of attitude within society regarding transport mode selection, or the modal shift towards public transport and cycling or walking. Concerning cycling, the effect of the "Cycle to Work" scheme could be investigated.

Within the sub-theme of public transport, the way in which commuters could be nudged towards this transport mode could be researched, with special emphasis on the differences between the two countries' public transport systems and also public attitudes. For instance, an 'experimental' travel mode switching could be investigated, where participants would be induced to temporarily change their mode of commuting, and the resulting temporary or permanent shift in modal choice but also modal perception could be investigated (similarly as in Abou-Zeid et al. [1], but with respect to local differences and further characteristics to be revealed). Perception of 'dead time' can also be analysed.

Still within the framework of public transport, measuring subjective well-being (SWB) also offers a perspective for future research. One way of achieving this could be using hedonimeters, like those applied in the 'mappiness' experiment ongoing in the UK (www.mappiness.org.uk).

Another wide ranging theme is that of traffic offences, which include, within the sub-theme of transport safety, speeding. But parking and free riding are also offences, where nudging the public towards law-abiding attitudes would be essential. The role of social networks in shaping intentions and behaviour could also be investigated [7].

Shifting transport from road to rail are, in case of freight transport, decisions which are dominantly influenced by costs and reliability. However, investigating the possibilities of introducing nudges in this area would provide a broad and far reaching theme. Unlike shifting freight to rail, nudging passengers to choose railway transport would not be such an unconventional theme of research and could be carried out complementary to or in exchange of research on nudges in public transport.

\section{Conclusion}

Behavioural economics has been gaining more and more relevance both nationally and internationally. This new approach towards decision making and choice architecture may have essential consequences not only within economics, but also for the transport sector. Nevertheless, there is a lack of field experiments in transport focusing on the merits and potential of using nudges and other tools of behavioural economics. Having shown the main elements and pillars of this discipline, and having also considered the relevant interrelated fields, the authors argue that behavioural economics is a new, emerging theme for the transport sector, which shall not be left undiscovered, but whose advantages need to be fully developed and deployed, among others, for the sake of transport safety and the possibility of reducing the adverse effects of climate change induced by transport operations.

\section{References}

1 Abou-Zeid M, Witter R, Bierlaire M, Kaufmann V, Ben-Akiva M, Happiness and travel mode switching: Findings from a Swiss public transportation experiment, Transport Policy, 19, 93-104.

2 Ariely D, Predictably Irrational, Harper Collins Publishers; New York, 2008, ISBN 978-0-06-135323-9.

3 Avineri E, On the use and potential of behavioural economics from the perspective of transport and climate change, Journal of Transport Geography, 24, (2012), 512-521, DOI 10.1016/j.jtrangeo.2012.03.003

4 Bamberg S, Fujii S, Friman M, Gärling T, Behaviour theory and soft transport policy measures, Transport Policy, 18, (2011), 228-235, DOI 10.1016/j.tranpol.2010.08.006

5 Dawney E, Behavioural economics: seven principles for policy makers, The New Economics Foundation; London, 2005, ISBN 190488203 X.

6 Danish Nudging Network, A network of organizations, institutions $\mathcal{E}$ companies, 2010, www . inudgeyou. com last accessed on 26/03/2013.

7 Darnton A, An overview of behaviour change models and their uses, GSR 
Behaviour Change Knowledge Review, Centre for Sustainable Development, University of Westminster.

8 Elliot M, Thomson J, Social cognitive determinants of offending drivers' speeding behaviour, Accident Analysis and Prevention, 42, (2010), 15951605, DOI $10.1016 /$ j.aap.2010.03.018

9 Ettema D, Friman M, Gärling T, Olsson L, Fujii S, How invehicle activities affect work commuters' satisfaction with public transport, Journal of Transport Geography, 24, (2012), 215-222, DOI 10.1016/j.jtrangeo.2012.02.007

10 Field M, Santarcangelo M, Sumnall H, Goudie A, Cole J, Delay discounting and the behavioural economics of cigarette purchases in smokers: the effects of nicotine deprivation, Psychopharmacology, 186(2), (2006), 255-263, DOI $10.1007 / \mathrm{s} 00213-006-0385-4$

11 Fuller R, Bates H, Gormley M, Hannigan B, Stradling S, Broughton P, Kinnear N, O'Dolan C, Conditions for Inappropriate High Speed: A Review of the Research Literature from 1995 to 2006, Road Safety Research Report, Vol. 92, Department for Transport; London, 2008, ISBN 9781906581329.

12 Gneezy U, Rustichini A, A Fine Is a Price, The Journal of Legal Studies, 29(1), (2000), 1-17, DOI $10.1086 / 468061$

13 Héder S, Egyszerúbb, olcsóbb manipulálni, mint tanítani, 15/12/2012, http://www.forlong.hu/blog/2012/12/15/ nudge-az-osztokeles-tudomanya/ last accessed at 01/04/2013.

14 Juhász M, Travel Demand Management - Possibilities of influencing travel behaviour, Periodica Polytechnica, 41, (2013). In press.

$15 \mathrm{Li}$ Y, Evaluating the Urban Commute Experience: A Time Perception Approach, Journal of Public Transportation, 6(4), (2003), 41-67.

16 Mátrai T, Cost benefit analysis and ex-post evaluation for railway upgrade projects, Periodica Polytechnica, 41. In press.
17 Metcalfe R, Dolan P, Behavioural economics and its implications for transport, Journal of Transport Geography, 24, 503-511.

18 Peer E, The time-saving bias, speed choices and driving behaviour, Transportation Research, Part F, 14, (2011), 543-554, DOI 10.1016/j.trf.2011.06.004

19 Peer E, Rosenbloom T, When two motivations race: The effects of timesaving bias and sensation-seeking on driving speed choices, Accident Analysis and Prevention, 50, (2013), 1135-1139, DOI 10.1016/j.aap.2012.09.002

20 Pelsmaker PD, Janssens W, The effect of norms, attitudes and habits on speeding behavior: Scale development and model building and estimation, Accident Analysis and Prevention, 39, (2007), 6-15, DOI 10.1016/j.aap.2006.05.011

21 Savage B, Knight T, Bacon J, Millington A, Bullock H, Buckland J, Behavioural Insights Toolkit, Social Research and Evaluation Division, Department for Transport; UK, 2011, ISBN 978-1-84864-130-3.

22 Scheiner J, Holz-Rau C, Gendered travel mode choice: a focus on car deficient households, Journal of Transport Geography, 24, (2012), 250-261, DOI 10.1016/j.jtrangeo.2012.02.011

23 Tapia W, Yermo J, Implications of Behavioural Economics for Mandatory Individual Account Pension Systems, OECD Working Papers on Insurance and Private Pensions, Working paper, Report No.:11.

24 Thaler RH, Sunstein CR, Advances in Behavioural Finance, Russell Sage Foundation; New York, 2005.

25 Thaler RH, Sunstein CR, Nudge - Improving Decisions About Health, Wealth, and Happiness, Yale University Press; New Haven and London, 2008.

26 Tversky A, Kahnemann D, The Framing of Decisions and the Psychology of Choice, Science, New Series, 211(4481), (1981), 453-458. 